\title{
Redefining Knowledge in the Digital Age
}

\author{
Martha Burkle ${ }^{1 \star}$, Cristobal Cobo ${ }^{2}$ ( $)$ \\ ${ }^{1}$ Social Sciences and Humanities Research Council (SSHRC), Canada \{mburkle@telus.net\} \\ 2Director of the Center for Research, Ceibal Foundation, Uruguay / Oxford Internet Institute, University of \\ Oxford, UK \{ccobo@fundacionceibal.edu.uy\}
}

Received on 17 April 2018; revised on 30 April 2018; accepted on 6 July; published on 15 July 2018

The digital era that started with the arrival of the Internet into our business, our higher education institutions, and our lives in one word, has dramatically changed the way we explore and produce knowledge. These are what we have considered some of the key drivers of this transformation

1. Decentralization and disintermediation, understood as the growing capacity of information and communication technologies (ICTs) for transforming access and use of information (Burkle \& Cobo, 2017; Becker et al., 2017). For the last decade, Internet has become a social sphere where communities can create and disseminate knowledge and information to others (C. Cobo, Scolari, \& Pardo Kuklinski, 2011). This phenomenon has not only diversified the mechanisms of knowledge production but has also disrupted what was traditionally understood as valid knowledge (Keen, 2015).

2. Massiveness and a growing demand. The access to higher education has significantly changed during the second half of the $20^{\text {th }}$ century and beyond. After the Second World War, individuals who had access to universities were part of the elite of their respective societies. In the 70 s and 90 s this situation changed into a larger portion of the society worldwide (with a growing demand of women to have access to university degrees, for example) (Trow, 2000). Moreover, with the expansion of the Internet, and the interest for expanding the sector of knowledgeable workers, an unprecedented demand for higher education was developed. Access to the Internet has influenced the phenomenon of commodification of knowledge, where knowledge is used, produced, and managed as a product or when knowledge processes are co-modified and mechanized.

3. New forms of knowledge production. The increasing connectedness and interdependence within societies in the $21^{\text {st }}$ Century has impacted how knowledge is being produced: the creation of new knowledge happens in a much more distributed way. Therefore, nowadays, production is not only more shared than some decades ago, it is also more collaborative (Plume \& van Weijen, 2014). Even more so, the expansion is not only in terms of volume but also in recognizing the importance of moving towards a more trans-disciplinary and interdisciplinary knowledge production (Gibbs, 2015; Enright \& Facer, 2016). Moreover, the expansion of new autonomous systems (artificial intelligence) capable of recognizing and interpreting text, sound, and image, are opening a whole new frontier in terms of artificial forms of new knowledge production, dissemination, validation and application.

*To whom correspondence should be addressed:

Social Sciences and Humanities Research Council (SSHRC)

350 Albert Street, Ottawa, ON, K1P 6G4, Canada
4. New means of knowledge recognition. Taking into account some of the drivers and trends already mentioned, it can be argued that forms and mechanisms to assess, validate, and knowledge recognition are also changing. This does not mean that the traditional forms of knowledge recognition (e.g. diploma, certificate) are not valid anymore, but there is a transition into new forms of assessing learning and new tools for assessing the impact of academic research are emerging (Wilsdon et al., 2017). New approaches are taken to validate, recognize, or authenticate novel forms of learning (Glover \& Malone, 2014). Today is not only relevant what knowledge do we have (or access) but also what can we do with the knowledge (adaptive expertise, up skilling, just-in-time learning).

\section{A FUTURE VISION FOR KNOWLEDGE CREATION AND DISSEMINATION: THE DIGITALIZATION OF UNIVERSITIES}

Higher education institutions are already learning from other sectors that offer intangible products and services, which can be easily digitized. New opportunities and threats are already impacting higher education institutions' ability to compete in the digital environment. Internet-based courses are now being revealed in the launch of massive open online courses (MOOCs) throughout the world. All these disruptions offer novel possibilities for democratizing access to education as well as open new threat and ethical challenges that need to be addressed.

New paths to explore the digitalization of higher education in the near future - targeting the construction of policy practicesis needed. We are convinced that the flexibility and fluidity that technologies bring to knowledge and networks could be further develop if we:

- Create and implement more flexible learning cultures and spaces where content is shared and received in multiple forms and modalities

- Implement new forms of learning access - such as virtual environments, online resources, mobile possibilities

- Establish multiple interactions with a diversity of networks beyond our original geographical places or disciplines

- Promote active connections between academia and industry, where knowledge access is flexible, relevant, learner oriented, and focused

- Facilitate interdisciplinarity and globalization of knowledge access, by creating platforms for mutual interaction across disciplines and countries

In the near future, knowledge access and knowledge construction will be built in a very different system to traditional forms of 
teaching and learning. We hope these lines are seen as a provocation to explore new venues, interact with new contents, and dream about what the future can bring.

\section{REFERENCES}

Becker, A., Cummins, M., Davis, A., Freeman, A., Hall Giesinger, C., \& Ananthanarayanan, V. (2017). NMC Horizon report: 2017 higher education edition. Austin, Texas: The New Media Consortium. Retrieved from: http://academedia.org/2017_NMC_horizon.pdf

Burkle, M. \& Cobo, C. (2017, July). Redefining knowledge in the Digital Age: Internet and Social Media. Paper presented at the Digitalization of the university of the future Summit, Hagen, Germany.

Cobo, C., Scolari, C., \& Pardo Kuklinski, H. (2011). Knowledge Production and Distribution in the Disintermediation Era. In M. Ciastellardi, C. M. de Almeida de Barros, \& C. A. Scolari (Eds.), McLuhan Galaxy Conference: understanding media today: Barcelona, May, 23rd-25th, conference proceedings (pp. 365-402). Barcelona: Universitat Oberta de Catalunya.

Gibbs, P. (2015). Transdisciplinary professional learning and practice. New York: Springer. doi:10.1007/978-3-319-11590-0

Glover, I. \& Malone, C. (2014). Towards the devolution of life wide learning awards through verifiable digital badges. In N. Jackson \& J. Willis (Eds.), Lifewide Learning and Education in Universities and Colleges. Lifewide Learning. Retrieved from: http://shura.shu.ac.uk/7885/

Keen, A. (2015). The Internet Is Not the Answer. New York: Atlantic Monthly Press.

Plume, A. \& van Weijen, D. (2014). Publish or perish? The rise of the fractional author. Research Trends, 38(2014). Retrieved from: https://www.researchtrends. com/issue-38-september-2014/publish-or-perish-the-rise-of-the-fractionalauthor/

Trow, M. (2000). From Mass Higher Education to Universal Access: The American Advantage. Minerva, 37(4), 303-328. doi:10.1023/A:1004708520977

Wilsdon, J. R., Bar-Ilan, J., Frodeman, R., Lex, E., Peters, I., \& Wouters, P. (2017). Next-generation metrics: responsible metrics and evaluation for open science (Report). Brussels: European Commission. Retrieved from: http://eprints. whiterose.ac.uk/113919/

Burkle, M. \& Cobo, C. (2018). Redefining Knowledge in the Digital Age. Journal of New Approaches in Educational Research, 7(2), 79-80. doi: $10.7821 /$ naer.2018.7.294 